$\stackrel{W}{=}$

Global burnals Inc.

है

\title{
Potassium Levels in COVID Subjects: Current Observations and New Possibilities for its use in COVID Diagnosis \\ By Sriram Padmanabhan
}

Abstract- Severe Acute Respiratory Syndrome Coronavirus-2 (SARS-CoV-2) causing covid infection in humans is a major global threat to healthcare and economy. According to the recent statistics of the World Health Organization (WHO), the disease has already involved all continents, with almost 117,498,522 cases with more than 2,606,626 deaths all over the globe until March 2021. It is thus, imperative to study and develop pharmacological treatments suitable for the prevention and treatment of COVID-19. The COVID causing virus is mainly transmitted through cough or sneeze droplets generated by an infected person. Hence its early and accurate diagnosis appears essential for minimizing spread, prevention and eventually containment of the pandemic. Also, since the clinical presentation of the COVID infection is varied starting from asymptomatic to severe cases, it reinforces the need for detection methods that are simple, early and with good sensitivity and specificity. This article reviews impact of potassium ions in functioning of various organs in humans and its possible role in COVID disease progression.

Keywords: potassium, ivermectin, favipiravir, remdisivir, coronavirus, SARS-CoV-2, COVID-19.

GJMR-K Classification: NLMC Code: WB 141

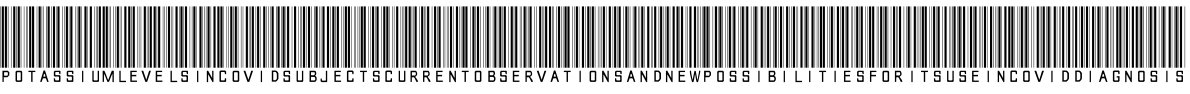

Strictly as per the compliance and regulations of:

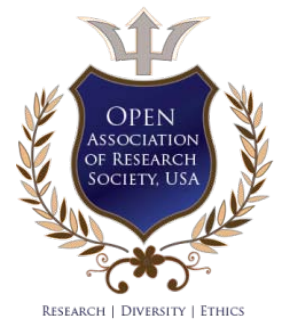

(C) 2021. Sriram Padmanabhan. This is a research/review paper, distributed under the terms of the Creative Commons AttributionNoncommercial 3.0 Unported License http://creativecommons.org/licenses/by-nc/3.0/), permitting all non-commercial use, distribution, and reproduction in any medium, provided the original work is properly cited. 


\title{
Potassium Levels in COVID Subjects: Current Observations and New Possibilities for its use in COVID Diagnosis
}

\author{
Sriram Padmanabhan
}

\begin{abstract}
Severe Acute Respiratory Syndrome Coronavirus-2 (SARS-CoV-2) causing covid infection in humans is a major global threat to healthcare and economy. According to the recent statistics of the World Health Organization (WHO), the disease has already involved all continents, with almost $117,498,522$ cases with more than $2,606,626$ deaths all over the globe until March 2021. It is thus, imperative to study and develop pharmacological treatments suitable for the prevention and treatment of COVID-19. The COVID causing virus is mainly transmitted through cough or sneeze droplets generated by an infected person. Hence its early and accurate diagnosis appears essential for minimizing spread, prevention and eventually containment of the pandemic. Also, since the clinical presentation of the COVID infection is varied starting from asymptomatic to severe cases, it reinforces the need for detection methods that are simple, early and with good sensitivity and specificity. This article reviews impact of potassium ions in functioning of various organs in humans and its possible role in COVID disease progression. Looking at the critical role of potassium ions in human body, it is speculated that estimation of potassium ions in the urine of covid patients could be beneficial and may enable early treatment options and arrest disease progression considerably. This article hypothesizes the possible role of active constituents of herbal medicines, known for their anti-covid properties, through balancing the level of potassium ions in the human body.

Keywords: potassium, ivermectin, favipiravir, remdisivir, coronavirus, SARS-CoV-2, COVID-19.
\end{abstract}

\section{INTRODUCTION}

( oronavirus disease 2019 (COVID-19), also known as severe acute respiratory syndrome coronavirus 2 (SARS-CoV-2), is caused by a strain of coronavirus belonging to the Coronaviridae family continues to spread around the world affecting the lives of billions of people worldwide. The International Committee on Taxonomy of Viruses (ICTV) has named the virus causing COVID infection as SARSCoV-2 [1, 2]. Many findings regarding COVID-19 etiology, epidemiology, diagnosis, and treatment strategies have been reported and it is evident that COVID affects almost all organs like heart, lungs, liver, kidney, brain, [3] causing loss of sense of taste and rashes in the skin.

Author: Head R \& D, Sava Healthcare Limited, Research Center, Block D1, Plot No. 17/6, MIDC, Chinchwad, Pune-411019, India.

e-mail:sriram.p@savaglobal.com
It has been suggested by Moreno-Péreza et al. [4] that serum potassium levels is a sensitive biomarker of severe progression of COVID-19, although the clinical significance of lower levels of potassium ions in serum of COVID patients is not clear. Lippi et al. [5] establish that COVID-19 severity is associated with lower serum concentrations of sodium, potassium and calcium.

A study conducted at Wenzhou Central Hospital and Sixth People's Hospital of Wenzhou, Wenzhou, China, observed various levels of plasma potassium incovid affected patients. Nearly $18 \%$ patients were classified as having severe hypokalemia (plasma potassium $3.5 \mathrm{mmol} / \mathrm{L}$ ), 37\% hypokalemia (plasma potassium 3-3.5 mmol/L), and $46 \%$ normokalemia (plasma potassium $>3.5 \mathrm{mmol} / \mathrm{L}$ ). From the above reports, it appears potassium levels could be potential indicators of covid progression. Patients with severe hypokalemia had higher body temperature, higher creatine kinase levels, higher lactate dehydrogenase levels and higher C-reactive protein levels. Patients with severe hypokalemia were given potassium at a dose of $40 \mathrm{mEq}$ per day and they responded well to potassium supplements as they recovered. Distribution of potassium across the cell membrane appears to be critical for normal cellular function [6].

To understand the impact of potassium level in covid subjects, I looked at all possible roles that potassium plays in human body and extrapolated these reports in covidscenario and a hypothesis in this regard is described in this paper.

\section{il. Plasma Potassium Levels and its Association With Angiotensin- Converting Enzyme 2 (ace2)}

ACE2, is the principal counter-regulatory mechanism for the main axis of the rennin-angiotensin system (RAS), which is critical in the control of blood pressure and electrolyte balance by balancing potassium and sodium [7]. The invasion of the human cells by the covid- 2 virus is through binding of the virus to the ACE2 receptors present on the surface of the cell membrane of human vital organs, such as heart, liver, kidney, and lungs. The low levels of potassium observed in COVID-19 patients possibly reflects a disordered rennin-angiotensin system activity, which increases as a 
result of reduced counter activity of angiotensinconverting enzyme 2 .

SARS-CoV-2 virus binds to ACE2 and enhances the degradation of ACE2 and, thus, decreases the counteraction of ACE2 on RAS. This leads to increased reabsorption of sodium and water, thereby increasing blood pressure and excretion of potassium [8]. In addition, patients with COVID-19 often have gastrointestinal symptoms, such as diarrhea and vomiting, leading to disruptions of homeostasis of electrolytes and $\mathrm{pH}$ [9].

a) Role of potassium in multiplication of other viruses

$\mathrm{K}^{+}$deficiency affects host-virus interactions by affecting the accessibility of virus attached to tissue and by affecting the intracellular synthesis of new virus. Since supplementation of potassium reverses such affects, it was concluded that such in-vitro effects of virus suppression was achieved by potassium depletion[10].

Choi et al. [11] showed 50\% decrease in HIV-1 production when the host cells of CD4+ lymphoblastoid cells infected by HIV-1 (strain LAl) was incubated in in low $\mathrm{K}+$ medium in comparison to a normal $\mathrm{K}+$ concentration $(5 \mathrm{mM})$. The decrease in HIV-1 production by low $\mathrm{K}+$ medium and increase by high $\mathrm{K}+$ media has been attributed to its effects on HIV-1 reverse transcription. Potassium is required for efficient viral replication and to induce cells for disease and infection.

$\mathrm{K}$ ions are reported to promote viral infection [12] since negative-stranded (SNS) 2 RNA viruses exposed to high $\mathrm{K}^{+}$also displayed enhanced infectivity.

\section{b) Potassium levels in other viral infections}

Viral infections, such as Dengue and Chikungunya, have also been reported to precipitate hypokalemic paralysis [13]. This is attributed to redistribution of potassium in cells or increased urinary potassium wasting as a result of transient renal tubular abnormalities.

\section{c) Role of anti-covid drugs and potassium levels}

\section{i. Ivermectin(IVM) and potassium}

Ivermectin, a highly active broad-spectrum, antiparasitic agent used to treat scabies [14], is a nonselective inhibitor of three important mammalian P-type ATPases. When used at high doses, IVM causes adverse effects [15]. With respect to the inhibition of the $\mathrm{Na}(+), \quad \mathrm{K}(+)$-ATPase, IVM acts by a mechanism different from the classical cardiac glycosides, based on selectivity towards the isoforms, sensibility to the antagonistic effect of $\mathrm{K}(+)$ and to ionic conditions favoring different conformations of the enzyme. Administration of IVM with or without albendazole to rats showed significant increase $(P<0.05)$ in serum potassium, urea, creatinine, glucose and cholesterol concentrations while serum albumin was significantly reduced $(P<0.05)[16]$.
Apart from its uses to address parasitic infections, IVM has been reported to inhibit the replication of COVID-2 virus [17] and identified as an inhibitor of interactions between the human HIV integrase protein and the importin $\alpha / \beta 1$ heterodimer. In COVID context, IVM is known to affect the nuclear transport of viral proteins that is essential for the replication cycle and inhibition of the host's antiviral response.

\section{ii. Potassium and Favipiravir}

Favipiravir, released in 2002 in Japan, as an inhibitor of influenza virus replication was subsequently proved to have inhibitory activity against several classes of viruses, including EBOV [18], and used as a prophylaxis and also for therapy during the recent EBOV epidemic in West Africa is an inhibitor of the RNAdependent RNA polymerase of many RNA viruses, including influenza viruses, arenaviruses, phleboviruses, hantaviruses, flaviviruses, enteroviruses, and noroviruses. QT interval, indicative of rate of heart beats is slower when QTC is prolonged and this has already been described in other EBOV-infected patients treated outside Africa and electrolyte disturbances, particularly hypokalaemia, may induce QTc interval prolongation [19].

Potassium levels $<3.0 \mathrm{mmol} / \mathrm{l}$ can be arrhythmogenic and specifically can cause QTc interval prolongation, hence the regulation and control of potassium levels in such patients is high. The cardiac involvement in SARS-CoV-2 is high (44.4\% of infected patients admitted to ICU experienced an arrhythmia) and hence the significance to maintaining normokalaemia in these patients is emphasized to reduce morbidity and mortality [20].

\section{iii. Remdisivir and potassium}

Remdesivir, an adenosine analogue, is a broad antiviral agent for filovirus, Ebola virus, Middle East respiratory syndrome coronavirus (MERS-CoV), Marburg virus, respiratory syncytial virus (RSV), HCV, pneumoviruses, coronaviruses and several paramyxoviruses. A potent inhibitor of SARS-CoV-2 replication, Remdesivir affects such viruses is in human nasal and bronchial airway epithelial cells [21]. A recent paper by Wang et al.[22] have shown increased levels of plasma potassium in patients treated with Remdisivir.

\section{d) Hypokalemia and cardiovascular disease}

Yadav et al. [23] report that in China, 27.8\% of admitted COVID-19 patients had myocardial injury mortality with higher elevated troponin levels causing death of $59.6 \%$ patient vs $8.9 \%$ death of patients with normal troponin levels [24]. Since nearly $7 \%$ to $17 \%$ of patients with cardiovascular disease have lower levels of plasma potassium levels, drugs, such as angiotensinconverting (ACE2) enzyme inhibitors, have a positive effect on mortality and morbidity rates in heart failure 
patients since they increase plasma potassium concentration.

\section{e) Herbal medications and potassium levels}

There are ample numbers of herbal drugs that can offer as a source of potassium [25]. Active phytoconstituents of medicinal plants such as Withania somnifera, Tinosporacordifolia and Ocimum sanctum have been found to affect the activity of the protease of SARS-CoV-2, affecting its multiplication [26]. Shimmi et al. [27] demonstrate that Withania somnifera treatment increases the level of potassium in serum of rats that were challenged with gentamycin. Similarly $T$. cordifolia dose-dependently has been shown to increase potassium levels [28]. It is tempting to speculate that the anti-covid activity of such plant extracts could also be through the route of balancing the levels of potassium ions in the human body which needs to be experimentally proven in COVID patients. There are some conflicting reports on inability of Glycyrrhiza glabra (licorice) extract to influence the potassium levels in humans [29] and the potassium levels were normal in 98.3\% patients with a dose of $8.7 \mathrm{~g}$ per day for 18 days. Also, some herbal drugs which are used a laxatives like Cassia senna L may lead to hypokalemia, since senna can cause excessive water and potassium loss. [30]. Hence, choice of herbal medicines to be taken for addressing potassium levels must be practiced with caution.

\section{f) Lung diseases and potassium levels}

Chronic Obstructive Pulmonary Disease (COPD) is a disease of increasing public health importance and COPD patients display typical features of acute respiratory infections like productive cough and dyspnoea along other metabolic derangements such as hyponatremia, hypokalemia, hyperbilirubinemia, elevated transaminases, elevated blood urea and elevated serum creatinine etc.[31]. Patients with COPD also show a slower rate of potassium exchange than the control subjects [32]. Levels of serum electrolytes e.g sodium, potassium, magnesium, and chloride are abnormal in patients with acute exacerbation of COPD and in particular the levels of potassium is $3.19 \pm 0.96$ $\mathrm{mEq} / \mathrm{l}$ in such patients in comparison to healthy controls (potassium $=4.50 \pm 0.02 \mathrm{mEq} / \mathrm{l}[33,34]$.

It is also consistent with reported associations between increased urinary potassium and increased airway hyper responsiveness [35] and also lower lung function in girls [36] and lower levels of serum potassium were associated with a greater risk of asthma [37]. However, there are studies that report no association of serum potassium and asthma. [38, 39].

\section{g) Potassium level in other diseases}

A recent study linked potassium with irritable bowel syndrome and showed that dietary potassium, was inversely correlated with risk of Crohn's disease in two large prospective cohorts of US women [40]. The levels of potassium had an inverse association with the disease activity in state of inflammation [41]. Hypokalemia is reported in several rheumatoid arthritis (RA) patients [42], which are reported to alleviate pain due to RA through diets rich in potassium.

In hyperaldosteronism (PHA), a disorder that is increasingly recognized as one of the most prevalent forms of secondary hypertension [43], there is hypokalemia due to an increased urinary potassium excretion. Similarly, a case of severe hypokalemia in a dementia patient [44] exists. Hypokalemic paralysis with low plasma potassium $(<3.5 \mathrm{mEq} / \mathrm{L})$ is caused either by an enhanced shift of potassium ion into the cells or following a significant renal or gastrointestinal loss of potassium[45].

h) Potassium level in urine as markers for disease progression

A study by Afridi et al. [46] show lower levels of calcium, potassium, magnesium and natrium in blood, serum and scalp hair of Acquired Immune Deficiency Syndrome (AIDS) suffering subjects in comparison to healthy controls, and the levels of these elements were higher in urine samples of the AIDS patients than in those of the control group, opening up a new possibility of examining levels of potassium as a measure of covid patients.

Khandelwal et al. [47] report low values of serum sodium (Hyponatremia) and potassium (hypokalemia) in dengue patients. The mean value of serum sodium was $133.92 \mathrm{mEq} / \mathrm{L}$ and of serum potassium was $3.62 \mathrm{mEq} / \mathrm{L}$ in such patients with more lower values in severely affected dengue patients in comparison to mildly affected dengue patients.

As SARS-CoVirus, Corona-2 virus also uses angiotensin converting enzyme 2 (ACE2) as a cell entry receptor [48]. Recent human tissue RNA-sequencing data demonstrated that ACE2 expression in kidney was nearly 100-fold higher than in lungs. Li et al. [49], hence the kidney disease may be caused by coronavirus entering kidney cells through an ACE2-dependent pathway. Hence, the possibility of having potassium in the urine of covid affected patients with acute kidney injury/necrosis appears high.

\section{i) Potassium and mental health}

70 percent of the ions that play a significant role electrical and cellular function in human cells is through potassium ions. Lower levels of potassium ions (between $2.7 \mathrm{mEq} / \mathrm{L}-3.3 \mathrm{mEq} / \mathrm{L}$ ) is known to cause mental tiredness, depression, mood swings, psychosis, muscular weakness, disorientation, nervousness and confusions [50].

The COVID-19 pandemic has implications in the emotional and social functioning of the affected patients. A recent publication report development of mental health issues such as depression, anxiety, 
insomnia within 3 months of diagnosis in 18\% of COVID-19 patients [51]. It is tempting to speculate that potassium supplementation in covid affected patients could improve such mental issues and such supplementations could be along with the regular antiviral regime that is prescribed to the affected patients. In normal health, serum potassium levels is between 3.5 to $5.2 \mathrm{mmol} / \mathrm{L}$ and disturbances in potassium levels have adverse effects on skeletal and cardiac muscle function [52] and lower potassium levels in urine samples indicates cardiac dysfunction [53]. It is possible that potassium supplementation can better the cardiac function and reduce the mortality due to cardiac failure in covid patients.

\section{j) Potassium estimation methods}

Potassium levels from spot urine specimens collected at any time has been successfully developed by Tanaka et al. [54] using emission flame photometry. The most commonly used methods are methods as described by Kawasaki et al.[55], Brown et al. [56] and Tanaka et al. [54].

\section{iil. Conclusions and Future Directions}

Potassium plays an important role (Normal serum potassium level $=3.5-5.0 \mathrm{mEq} / \mathrm{L}$ ) in regulation of the heart beat and function of muscles. Along with sodium, potassium is also involved in regulation of water and acid-base balance in blood and tissue [57]. In mammals, the osmotic pressure and water distribution maintenance is the primary function of electrolytes such as sodium and potassium and these ions play a role in maintenance of $\mathrm{pH}$, in oxidation reduction reactions, in heart muscle functioning and as cofactors for enzymes [58] and the body restores potassium balance by shifting the plasma potassium into cells or by renal elimination.

The new coronavirus is reported to cause low potassium levels because it blocks an enzyme called ACE2 that regulates blood pressure by balancing potassium and sodium. $\mathrm{Mg}^{+2}$ and $\mathrm{K}^{+}$participate in several biochemical processes and its deficiency affects lung function and also influence respiratory symptoms. Increased airway sensitiveness is reported to be associated with a higher urinary potassium excretion [59].

Presence of covid virus in the body fluid such as urine is contradictory. While Wang et al. [60] report the presence of SARS-CoV-2 in sputum (72\%), fibrobronchoscope brush biopsy (46\%), pharyngeal swabs (32\%), feces (29\%), and blood (1\%) and no detection of virus in urine samples suggesting that the transmission of the SARS-CoV-2 is by the fecal route [61]. However, a recent study by Peng et al. [62] could detect the covid virus in 1 sample of urine of the 9 patients tested (11\%). Ling and colleagues [63] reported 66 patients with COVID-19 from Shanghai, China. Urine samples of 4 patients (6.9\%) were positive for COVID19. In 3 patients, urinary samples were positive even after clearance of virus in oropharyngeal samples.

Tinospora cordifolia is reported for covid use. It has high potassium $(0.845 \%)$ and could be playing a role in improving the hypokalemia status in covid patients [64]. Use of drugs that promote potassium loss like hydrochlorothiazide must be avoided. Further, the decreased potassium levels in conditions such as chronic renal failure, were restored to normal by day 30 in Boerhaavia diffusa root extract treatment, which can be attributed to the potassium nitrate content $(6 \%)$ in the $B$. diffusa root extract [65]. Withania somnifera root extract may have some role in maintaining some of the serum electrolyte levels especially potassium within normal limit [27].

In addition to respiratory organs, up-regulation of ACE2 expression was also identified in urogenital system including kidney proximal tubule cells, bladder urothelial cells and genital organs including testis. Since the hypokalemia effect has been monitored and found to last more than 5 months in subjects with COVID-19 pulmonary infection and continued to have hypokalemia and even after the disappearance of the common COVID-19 symptoms [66], the suggestion of examining the estimation of potassium in urine of covid patients assumes critical importance. Since COVID-19 is detected in urine of infected individuals, infection transmission through urine remains possible, hence medical interventions like endoscopy and urethral catheterization for covid patients' needs to be done with care and caution [67].

Acute kidney injury (AKI) represents reduced glomerular filtration rate and/or reduced urine flow associated with mortality which is a regular feature in COVID-19 disease. Biomarkers of tissue damage e.g. creatinine may identify patients of particular risk [68]. Burns and $\mathrm{Ho}$ [69] report the higher levels of potassium in the urine of acute kidney injury patients, supporting our hypotheses in diagnosis of covid patients by measuring urine potassium levels. AKI has been found to be an independent risk factor for death in hospitalized COVID-19 patients [70], hence detection of covid virus in the urine might indicate possible kidney injury as described by de Souza et al. [71]. Also, in COVID patients, due to gastrointestinal disturbances, there is loss of water and electrolytes in the body, which is associated with diarrhea. Treatment of such patients with adequate water and electrolyte helps [72].

For the suggestion of testing urine of covid patients for the detection of virus genetic material requires no additional requirements than what is carried out presently with the nasopharyngeal (NP) swab and/or an oropharyngeal (OP) swab of the suspected/affected patient and then the isolation of RNA of the covid virus is carried out in a biosafety level III lab. The viral RNA is then subjected to RT-PCR that requires trained and 
skilled personnel and also facilities for handling PCR products in air-controlled laboratories. Hence, the recommendation of Goudoris et al. [73] that the diagnosis of COVID-19 should be based on clinical data, epidemiological history and new diagnostic methods with higher sensitivity and specificity, as well as faster results, appears relevant and essential.

Rapid antigen lateral flow assays, although is rapid and low-cost for detection of SARS-CoV-2, it suffers from poor sensitivity early in infection [74]. Infectious SARS-CoV-2 was successfully isolated from urine of a COVID-19 patient and since the isolated virus isolated could infect new susceptible cells, it was emphasized that urine samples must be handled with care [75], however damage to kidney is ruled out [76].

Since the early diagnosis of covid would reduce spread of the disease, I believe the present hypothesis of using potassium estimation in urine of covid patients as results of diagnostic tests will have significant and beneficial implications for minimizing risks for health professionals and humans in general. Although Liu et al. [77] found that COVID disease severity could be predicted by lower counts of lymphocytes, neutrophils, albumin and increased values of LDH and CRP, the present observations of novel associations of potassium ions in viral diseases in general, tempts me to suggest examination of potassium levels in the urine of COVID patients' although, this merits further investigation.

Genetic variation in covid virus have been reported to be restricted to the gene coding for the spike protein [78, 79] and such mutations have been suggested to play a prominent role in viral transmission and overall stability of the virus. In the recent past, the United Kingdom has faced a rapid surge in COVID-19 cases and genome mapping has indicated multiple mutations in the spike protein gene and mutations in other genomic regions of the viral genome. Studies have shown that these variants are more transmissible than previously circulating variants [80]. Nearly $14 \%$ of SARSCoV-2 variants were not detectable by RT-PCR using commercialized primers [81], hence one cannot ascertain that the employed methods of covid virus detection like RT-PCR might not yield false negative results. The currently described hypothesis of estimation of potassium ions in urine of covid patients will not be affected by such mutations and hence in all probabilities might serve as a fool-proof method for detection of covid-19 infection.

A recent study with 290 non-ICU admitted patients with COVID-19 in a hospital of Modena, Italy has revealed an increase of urinary potassium excretion in almost $95.5 \%$ cases [82] while another study with 175 patients where patients were classified based on serum potassium levels were found to improve by potassium supplementation through the use of potassium chloride at a daily dose of $40 \mathrm{mEq}$ per day [83]. These recent reports do support the significance of monitoring potassium levels in covid-19 patients and hence the current proposal of estimation of urinary potassium levels in covid-19 patients will benefit clinicians for faster diagnosis and initiation of treatment.

Funding

This research received no specific grant from any funding agency in the public or commercial sector.

Declaration of Competing Interest

The author declares that there are no known competing financial interests or personal relationships that could have appeared to influence the work reported this paper.

\section{AcKnOWLedgements}

The author thanks Mr. Vinod Jadhav, Chairman, SAVA Healthcare Limited and Mr. Avinaash Mandale, Managing Director, SAVA Healthcare Limited for being a constant source of support and encouragement.

\section{References Références Referencias}

1. Rothan HA, Byrareddy SN. The epidemiology and pathogenesis of coronavirus disease (COVID-19) outbreak. J Autoimmun 2020; 109: 102433. doi: 10.1016/j.jaut.2020.102433.

2. Cui J, Li F, Shi ZL. Origin and evolution of pathogenic coronaviruses. Nat Rev Microbiol 2019; 17(3): 181-92. https://doi.org/10.1038/s41579-0180118-9

3. Jain U. Effect of covid-19 on the organs. Cureus 2020; 12(8): e9540. doi: 10.7759/cureus.9540

4. Moreno-Péreza O, Leon-Ramirezc J-M, FuertesKenneally L, et al. Hypokalemia as a sensitive biomarker of disease severity and the requirement for invasive mechanical ventilation requirement in COVID-19 pneumonia: A case series of 306 Mediterranean patients. Int. J infect Dis 2020; 100: 449-54.https://doi.org/10.1016/j.jijid.2020.09.033

5. Lippi G, South AM, Henry BM. Electrolyte imbalances in patients with severe coronavirus disease 2019 (COVID-19). AnClinBiochem 2020; 57 (3): 262-265. doi: 10.1177/0004563220922255

6. [Palmer BF, Clegg DJ. Physiology and pathophysiology of potassium homeostasis. AdvPhysiolEduc 2016; 40(4): 480-490. https:// doi.org/10.1152/advan.00121.2016

7. Santos RA, Ferreira AJ, Simões E, Recent advances in the angiotensin-converting enzyme 2-angiotensin (1-7)-Mas axis. ExpPhysiol 2008; 93(5): 519-527. doi:10.1113/expphysiol.2008.042002

8. Weir MR, Rolfe M. Potassium homeostasis and renin-angiotensin-aldosterone system inhibitors. Clin J Am SocNephrol 2010; 5(3): 531-548. doi:10.2215/CJN.07821109

9. Wang D, Hu B, Hu C, et al. Clinical characteristics of 138 hospitalized patients with 2019 novel coronavirus- infected pneumonia in Wuhan, China. 
JAMA 2020; 323(11): 1061-1069. doi: 10.1001/ jama.2020.1585

10. Levine AS, Bond PH, Scala AR. et al. Studies on the relationship of potassium to influenza virus multiplication. J Immunol 1956; 76 (5): 386-92.

11. Choi B, Gatti PJ, Haislip AM, et al. Role of potassium in human immunodeficiency virus production and cytopathic effects. Virology 1998; 247(2): 189-99. doi: 10.1006/viro.1998.9251.

12. Punch EK, Hover S, Blest HTW, et al. Potassium is a trigger for conformational change in the fusion spike of an enveloped RNA virus. J BiolChem 2018; 293(26): 9937-9944. Doi: 10.1074/jbc.RA118. 002494

13. Gutch $M$, Agarwal A, Amar A. Hypokalaemicquadriparesis: An unusual manifestation of dengue fever. $J$ Nat SciBiol Med 2012; 3(1): 81-83. doi: 10.4103/0976-9668.95976.

14. Chandler RE. Serious neurological adverse events after Ivermectin-Do they occur beyond the indication of onchocerciasis? Am J Trop Med Hyg 2018; 98(2): 382-388. doi: 10.4269/ajtmh.17-0042

15. Pimenta PHC, Silva CLM, Noël F. Ivermectin is a nonselective inhibitor of mammalian P-type ATPasesNaunynSchmiedebergs Arch Pharmacol 2010; 381(2): 147-152. doi: 10.1007/s00210-0090483-z.

16. Arise RO, Malomo SO. Effects of ivermectin and albendazole on some liver and kidney function indices in rats. Afr J Biochem Res 2009; 3 (5): 190197.https://doi.org/10.5897/AJBR.9000102

17. Caly L, Druce JD, Catton MG, et al. The FDA approved drug Ivermectin inhibits the replication of SARS-CoV-2 in vitro. Antiviral Res 2020; 178: 104787. https://doi.org/10.1016/j.antiviral.2020. 104787

18. Oestereich L, Lüdtke A, Wurr S. et al. Successful treatment of advanced Ebola virus infection with $\mathrm{T}$ 705 (favipiravir) in a small animal model. Antiviral Res 2014; 105: 17-21.doi: 10.1016/j.antiviral. 2014.02.014.

19. Chinello P, Petrosillo N, Pittalis S, et al. QTc interval prolongation during favipiravir therapy in an Ebolavirus-infected patient. PLoSNegl Trop Dis 2017; 11(12): e0006034. https://doi.org/10.1371/ journal.pntd.0006034

20. Mabillard H, Sayer JA. Electrolyte disturbances in SARS-CoV-2 infection.F1000 Res 2020; 9, 587.doi: 10.12688/f1000research.24441.2.

21. Pizzorno A, Padey B, Julien T, et al. Characterization and treatment of SARS-CoV-2 in nasal and bronchial human airway epithelia. Cell Reports Med 2020; 1: 100059. DOI:10.1101/2020.03.31.017889

22. Wang $Y$, Zhang D, Du G, et al. Remdesivir in adults with severe COVID-19: a randomized, double-blind, placebo-controlled, multicentre trial. Lancet 2020;
395: 1569-1578. https://doi.org/10.1016/S01406736(20)31022-9

23. Yadav R, Bansal R, Budakoty S, et al. COVID-19 and sudden cardiac death: A new potential risk. Indian Heart J 2020; 72(5): 333-336. doi: 10.1016/ j.ihj.2020.10.001

24. Guo T, Fan Y, Chen M. Cardiovascular implications of fatal outcomes of patients with Coronavirus disease 2019 (COVID-19). JAMA Cardiol 2020; 5(7): 811-818. doi: 10.1001/jamacardio.2020.1017.

25. Krstic-Pavlovic N, Zamic RD, Jelacic S. Potassium contents in some medicinal plants. ActaHortic 1992; 306: 245-248. DOI: 10.17660/ActaHortic.1992. 306.29

26. Shree $P$, Mishra $P$, Selvaraj $C$, et al. Targeting COVID-19 (SARS-CoV-2) main protease through active phytochemicals of ayurvedic medicinal plants -Withaniasomnifera (Ashwagandha), Tinosporacordifolia (Giloy) and Ocimum sanctum (Tulsi) - a molecular docking study. J BiomolStrucDyn 2020; 1-14.

27. Shimmi S, Jahan N, Sultana N. Effects of Ashwagandha (Withaniasomnifera) root extract against gentamicin induced changes of serum electrolytes in rats. J Bangladesh SocPhysiol 2012; 7(1): 29-35 https://doi.org/10.3329/jbsp.v7i1.11157 https://doi.org/10.1080/07391102.2020.1810778.

28. Sharma AK, Kishore K, Sharma D, et al. Cardioprotective activity of alcoholic extract of Tinosporacordifolia (Willd.) Miers in calcium chloride-induced cardiac arrhythmia in rats. J Biomed Res 2011; 25(4), 280-286. doi: 10.1016/S1674-8301(11)60038-9

29. Jung W-S, Kwon S-W, Im J-W, et al. Influence of herbal complexes containing licorice on potassium levels: A retrospective study. Evidence-Based Complementary and Alternative Medicine, 2014; 2014: ID 970385.

30. Williamson E, Driver S, Baxter K, et al. Stockley's Herbal Medicines Interactions (2009). 1st ed. London: Pharmaceutical Press; UK.

31. Mohan A, Premanand R, Reddy LN. et al. Clinical presentation and predictors of outcome in patients with severe acute exacerbation of chronic obstructive pulmonary disease requiring admission to intensive care unit.BMC Pulm Med. 2006; 6: 27.doi: 10.1186/1471-2466-6-27.

32. Telfer N, Weiner JM, Merrill Q. Distribution of sodium and potassium in chronic obstructive pulmonary disease Am Rev Respir Dis 1975; 111(2): 166-176. doi: 10.1164/arrd.1975.111.2.166.

33. Das $P$, Bandyopadhyay $M$, Baral $K$, et al. Dyselectrolytemia in Chronic obstructive pulmonary diseases with acute exacerbation. Nig J PhysiolSci 2010; 25(1): 25-7.

34. Maklad SF, Basiony FS. Electrolyte disturbances in patients with acute exacerbation of chronic 
obstructive pulmonary disease. The Scientific Journal of Al-Azhar Medical Faculty, Girls.2019; 3, 427-31.

35. Sparrow D, O'Connor GT, Rosner B, et al. Methacholine airway responsiveness and 24-hour urine excretion of sodium and potassium. The Normative Aging Study. Am Rev Respir Dis 1991; 144: 722-25.

36. Gilliland FD, Berhane KT, Li YF, et al. Dietary magnesium, potassium, sodium, and children's lung function. Am J Epidemiol 2002; 155(2): 125-31.

37. Gustafson T, Boman K, Rosenhall L, et al. Skeletal muscle magnesium and potassium in asthmatics treated with oral beta(2)-agonists. EurResp J 1996; 9(2): 237-240. http://dx.doi.org/10.1155/2014/ 970385.

38. Fantidis $P$, Ruiz CJ, Marin $M$, et al. Intracellular (polymorphonuclear) magnesium content in patients with bronchial asthma between attacks. J R Soc Med 1995; 88(8): 441-445.

39. Alamoudi OS. Electrolyte disturbances in patients with chronic, stable asthma: effect of therapy. Chest 2001; 120(2): 431-436. doi: 10.1378/chest.120. 2.431 .

40. Awasthi A, Malik S, Khalili, H. Identification and characterization of a novel association between dietary potassium and risk of Crohn's disease and ulcerative colitis. Front Immunol 2017; 198(1): 554.doi: 10.3389/fimmu.2016.00554.

41. Goyal S, Rampal R, Kedia S, et al. Urinary potassium is a potential biomarker of disease activity in ulcerative colitis and displays in vitro immunotolerant role. Scientific Reports 2017; 7, 18068. doi:10.1038/s41598-017-18046-x

42. Kianifard T, Chopra A. A therapeutic role for potassium $(K)$ to reduce pain and complications related to the cardiovascular system and bone in rheumatoid arthritis (RA): A clinical research perspective. 2918; 3(1): 1-12. doi; 10.22631/rr.2017. 69997.1035

43. Funder JW, Carey RM, Mantero F, et al. The management of primary aldosteronism: case detection, diagnosis, and treatment: an endocrine society clinical practice guideline. J ClinEndocrinolMetab 2016; 101(5): 1889-1916. doi: 10.1210/jc.2015-4061

44. Nishiyama N, Takeshita M, Tanaka K. et al. A case of severe hypokalemia caused by a Chinese herbal remedy (Yokukansan) in an 81-year-old woman with dementia. Nihon Ronen IgakkaiZasshi 2011; 48(5), 553-57.doi: 10.3143/geriatrics.48.553.

45. Garg RK, Malhotra HS, Verma R, et al. Etiological spectrum of hypokalemic paralysis: A retrospective analysis of 29 patients Ann Indian AcadNeurol 2013; 16(3): 365-370. doi: 10.4103/0972-2327.116934

46. Afridi HI, Kazi TG, Talpur FN, et al. Evaluation of calcium, magnesium, potassium and sodium in biological samples of male human immunodeficiency virus patients with tuberculosis and diarrhea compared to healthy control subjects in Pakistan. Clin Lab 2013; 59(5-6): 539-550. doi: 10.7754/clin.lab.2012.120517.

47. Khandelwal VG, Patil VC, Botre A, et al. Electrolyte disturbances in dengue infected patients. Int $J$ Contemp Med Res 2019; 6(2): B5-B8. doi: http://dx.doi.org/10.21276/ijcmr.2019.6.2.14

48. Peiris JSM, Chu CM, Cheng VCC.et al. Clinical progression and viral load in a community outbreak of coronavirus-associated SARS pneumonia: a prospective study. Lancet 2003; $361(9371)$ : 176772.doi: 10.1016/s0140-6736(03)13412-5.

49. Li Z, Wu M, Guo J. et al. Caution on kidney dysfunctions of 2019-nCoV patients 2020. 2020; MedRxiv. https://doi.org/10.1101/2020.02.

50. Gitlin D. Hypokalemia and Hypomagnesemia, in Handbook of Medicine in Psychiatry. (2006). Edited by Manu P, Suarez RE, and Barnett BJ. Washington, DC, American Psychiatric Publishing, USA.

51. Pfefferbaum B, North CS. Mental Health and the Covid-19 Pandemic. N Engl J Med 2020; 383: 510512. doi: 10.1056/NEJMp2008017

52. Kjeldsen K. Hypokalemia and sudden cardiac death. ExpClinCardiol 2010; 15(4): e96-e99.

53. Kieneker LM, Gansevoort RT, Boer RA. et al. Urinary potassium excretion and risk of cardiovascular events. Am J ClinNutr 2016; 103(5): 1204-12. doi: 10.3945/ajcn.115.106773.

54. Tanaka T, Okamura T, Miura K, et al. A simple method to estimate populational 24-h urinary sodium and potassium excretion using a casual urine specimen. Journal of Human Hypertension 2002; 16: 97-103. doi: 10.1038/sj/jhh/1001307

55. Kawasaki $\mathrm{T}$, Itoh $\mathrm{K}$, Uezono $\mathrm{K}$, et al. A simple method for estimating $24 \mathrm{~h}$ urinary sodium and potassium excretion from second morning voiding urine specimen in adults. ClinExpPharmacolPhysiol 1993; 20(1): 7-14. doi: 10.1111/j.1440-1681.1993. tb01496.x.

56. Brown IJ, Dyer AR, Chan Q, et al. Estimating 24hour urinary sodium excretion from casual urinary sodium concentrations in Western populations: the INTERSALT study. Am J Epidemiol 2013; 177: 1180-92.doi: 10.1093/aje/kwt066.

57. Godkar P. Determination of ions and automation. (20040. Clinical Biochemistry: principles and practices; Godkar P, 2nd edition". Bhalani Publishing House, pp 57-68.

58. Burtis CA, Bruns DE. (2008). Teitz Fundamentals of Clinical Chemistry; 6th edition". Elsevier Saunders publishers. pp. 432.

59. Pistelli R, Forastiere F, Corbo GM. et al. Respiratory symptoms and bronchial responsiveness are related to dietary salt intake and urinary potassium 
excretion in male children. EurRespir J 1993; 6(4): 517-22.

60. Wang W, Xu Y, Gao R, et al. Detection of SARSCoV-2 in different types of clinical specimens. JAMA 2020; 323(18): 1843-1844. doi: 10.1001/jama.2020. 3786

61. Bwire GM, Majigo MV, Njiro BJ, et al. Detection profile of SARS-CoV-2 using RT-PCR in different types of clinical specimens: A systematic review and meta-analysis. J Med Virol 2021; 93: 719-725. doi: 10.1002/jmv.26349

62. Peng L, Liu J, Xu W. et al. SARS-CoV-2 can be detected in urine, blood, anal swabs, and oropharyngeal swabs specimens. J Med Virol 2020; 92(9): 1676-80. Doi:10.1002/jmv.25936.

63. Ling $Y, X u$ S-B, Lin $Y-X$. et al. Persistence and clearance of viral RNA in 2019 novel coronavirus disease rehabilitation patients. Chin Med $J$ (Engl) 2020; 133(9): 1039-1043. doi: 10.1097/CM9. 0000000000000774

64. Singh S, Maan NS, Rana V, et al. Effect of dietary inclusion of Giloy (Tinosporacordifolia) stem powder on growth performance and metabolizability in broilers. J EntomolZoolStud 2018; 6(5): 36-40.

65. Oburai NL, Rao VV, Bonath RBN. Comparative clinical evaluation of Boerhaviadiffusa root extract with standard Enalapril treatment in canine chronic renal failure. J Ayurveda Integr Med 2015; 6(3): 15057. doi: 10.4103/0975-9476.166390

66. Alnafiey $\mathrm{MO}$, Alangari AM, Alarifi $\mathrm{AM}$, et al. Persistent Hypokalemia post SARS-coV-2 infection, is it a life-long complication? Case report Ann Med Surg (Lond). 2021; 62: 358-61. doi: 10.1016 /j.amsu.2021.01.049

67. Kashi AH, Rosette JDL, Amini E, et al. Urinary viral shedding of covid-19 and its clinical associations: A systematic review and meta-analysis of observational studies. Urol J 2020; 17(5): 433-441. doi: 10.22037/uj.v16i7.6248.

68. Luther T, Bülow-Anderberg S, Larsson A. et al. COVID-19 patients in intensive care develop predominantly oliguric acute kidney injury. ActaAnaesthesiolScand 2021; 65(3), 364-72.doi: 10.1111/aas.13746.

69. Burns AR, Ho KM. Urinary potassium excretion and its association with acute kidney injury in the intensive care unit. J Crit Care 2018; 46: 58-62. doi: 10.1016/j.jcrc.2018.04.009.

70. Cheng $Y$, Luo R, Wang $K$, et al. Kidney disease is associated with in-hospital death of patients with COVID-19. Kidney Int2020; 97(5): 829-38. doi: https://doi.org/10.1016/j.kint.2020.03.005

71. de Souza SP, Silveira MAD, de FreitasSouza BS, et al. Evaluation of urine SARS-COV-2 RT-PCR as a predictor of acute Kidney Injury and disease severity in critical COVID-19 patients. 2020; Medrxivdoi: https://doi.org/10.1101/2021.01.13.21249576
72. Taheri M, Bahrami A, Habibi $\mathrm{P}$, et al. A review on the serum electrolytes and trace elements role in the pathophysiology of COVID-19. Bio Trace Elem Res 2020; 2020: 1-7. https://doi.org/10.1007/s12011020-02377-4.

73. Goudouris ES. Laboratory diagnosis of COVID-19.J Pediatr (Rio J) 2021; 97(1): 7-12. doi: 10.1016/ j.jped.2020.08.001

74. Tang Y-W, Schmitz JE, Persing DH, et al. Laboratory diagnosis of COVID-19: current issues and challenges. J ClinMicrobiol 2020; 58: e00512-20. https://doi.org/10.1128/JCM.00512-20

75. Sun J, Zhu A, Li H, et al. Isolation of infectious SARS-CoV-2 from urine of a COVID-19 patient. Emerg Microbes Infect 2020; 9(1): 991-93. doi: 10.1080/22221751.2020.1760144

76. Frithiof $R$, Bergqvist $A$, Jarhult $J$, et al. Presence of SARS-Cov-2 in urine is rare and not associated with acute kidney injury in critically ill COVID-19 patients. Critical Care 2020; 24:587-588. https://doi.org/10.1186/s13054-020-03302-w

77. Liu $Y$, Yang $Y$, Zhang $C$. et al. Clinical and biochemical indexes from 2019-nCoV infected patients linked to viral loads and lung injury. Sci China Life Sci 2020; 63 (3): 364-374. doi: 10.1007/s11427-020-1643-8.

78. Zhang L, Jackson CB, Mou H, et al. SARS-CoV-2 spike-protein D614G mutation increases virion spike density and infectivity. Nat Commun 2020;11: 6013. https://doi.org/10.1038/s41467-020-19808-4

79. Laha S, Chakraborty J, Das S. Characterizations of SARS-CoV-2 mutational profile, spike protein stability and viral transmission. Infect Genet Evol 2020; 85, 104445. https://doi.org/10.1016/ j.meegid.2020.104445.

80. European Centre for Disease Prevention and Control. (December 2020). Rapid increase of a SARS-CoV-2 variant with multiple spike protein mutations observed in the United Kingdom, ECDC: Stockholm.

81. Afzal A. Molecular diagnostic technologies for COVID-19: Limitations and challenges. J Adv Res 2020; 26: 149-159. doi: 10.1016/j.jare.2020.08.002

82. Alfano $G$, Ferrari $A$, Fontana $F$, et al. Hypokalemia in patients with COVID-19. Clin Exp Nephrol 2021; 25: 401-409. https://doi.org/10.1007/s10157-020-019 96-4

83. Chen $\mathrm{D}$, Li $X$,Song $Q$, et al. Assessment of hypokalemia and clinical characteristics in patients with coronavirus disease 2019 in Wenzhou, China. JAMA Network Open. 2020; 3(6): e2011122. doi:10.1001/jamanetworkopen.2020.11122 